\title{
Project Based Learning For Brush Less DC Motor
}

\author{
Ihtiari Prastyaningrum, Pramudya Ardi \\ Electrical Engineering Education, Faculty of Teacher Training and Education \\ Universitas PGRI Madiun,
}

Second College of Universitas PGRI Madiun Jalan Auri No. 6 Kota Madiun Indonesia

Email: ihtiari.prastya@unipma.ac.id

\begin{abstract}
The rapid development of technology demands that the younger generation be more creative and innovative to develop themselves. As we know, the current supply of fossil fuels is running low, and of course this is a challenge for the younger generation. Facing this, there are currently many electricbased motorized vehicles being developed which hope that in the future they will be able to develop and have wider utilization. One of the choices is an electric motor. In order to support the development of electric vehicles, the Electrical Engineering Education Study Program of the PGRI Madiun University, is trying to develop an electric motor based on a BLDC motor or Brushless DC Motor. Where understanding the concept first emphasized so that students better understand the work system of this motor BLDC. Through project-based learning, students can understand more quickly about the BLDC motor work system. The results showed an increase in understanding of the concept of the work system of BLDC MOTOR. The boost has a medium N-Gain value. From these results, it can be concluded that through project-based learning for BLDC motors, it can improve understanding of the concept of the BLDC motor work system.
\end{abstract}

Keywords: motor, BLDC motor, project, concept, magnetic field

\begin{abstract}
Abstrak: Perkembangan teknologi yang semakin pesat menuntut generasi muda juga lebih kreatif dan inovatif untuk mengembangkan dirinya. Seperti telah kita ketahui bahwa saat ini persediaan bahan bakar fosil semakin menipis, dan tentu saja ini menjadi tantangan tersendiri bagi generasi muda. Menghadapi hal ini, maka saat ini banyak dikembangkan kendaraan bermotor berbasis listrik yang harapan kedepannya nanti akan mampu berkembang dan pemanfaatannya lebih luas. Salah satu yang menjadi pilihan adalah motor listrik. Guna mendukung perkembangan kendaraan listrik, Program Studi Pendidikan Teknik Elektro Universitas PGRI Madiun, mencoba mengembangkan motor listrik berbasis BLDC motor atau Brushless DC Motor . Dimana pemahaman konsep terlebih dahulu ditekankan agar mahasiswa lebih memahami sistem kerja dari BLDC motor ini. Melalui pembelajaran berbasis proyek, mahasiswa dapat lebih cepat memahami tentan sistem kerja BLDC motor . Hasil penelitian menunjukkan adanya peningkatan pemahaman konsep mengenai sistem kerja dari BLDC MOTOR . Peningkatan memiliki nilai N-Gain medium. Dari hasil tersebut maka dapat disimpulkan bahwa melalui pembelajaran berbasis proyek untuk BLDC motor mampu meningkatkan pemahaman konsep mengenai sistem kerja BLDC motor .
\end{abstract}

Kata kunci : motor, BLDC motor, proyek, konsep, medan magnet

\section{PENDAhUluan}

Dewasa ini perkembangan kendaraan bermotor semakin pesat. Jumlah kendaraan bermotor yang semakin meningkat menimbulkan tingginya polusi udara serta kelangkaan bahan bakar fosil. Berdasarkan penuturan menteri ESDM permintaan energi nasional terus mengalami peningkatan setiap waktunya. Hal berbanding lurus dengan adanya perkembangan teknologi, perekonomian nasional, maupun perubahan gaya hidup. Namun dalam hal ini peningkatan konsumsi energi tersebut dapat berpotensi memperburuk neraca dagang nasional. Hal tersebut karena penggunaan energi nasional didominasi oleh bahan bakar fosil. Berdasarkan data dari Indonesian Energi Otlook 2019, tahun 2018, total konsumsi energi fial (tanpa biomasa 
tradisional) berkisar 114 MTOE. Kebutuhan ini terdiri dari sektor transportasi 40\%, industri $36 \%$, rumah tangga $16 \%$, komersial dan sektor lainnya masing-masing $6 \%$ dan $2 \%$. Dari data tersebut terlihat jelas, bahwa konsumsi energi terbesar adalah pada sektor transportasi.

Dominasi penggunaan bahan bakar fosil membuat cadangan energi yang semakin menipis. Data menunjukkan bahwa cadangan batu bara saat ini sekitar 7,3-8,3 miliar ton yang diprediksi akan habis pada 2036. Sementara itu, stok minyak saat ini sebesar 3,7 miliar barrel diprediksi akan habis pada 2028. Untuk bahan bakar gas, cadangannya sebesar 151,33 trilion cubic feet (TCF) dan diprediksi habis pada 2067. Oleh karena itu, pemerintah terus menggalakkan pengelolaan energi baru terbarukan sebagai alternatif kebutuhan bahan bakar fosil (Suharyati et al, 2019).

Pengelolaan energi baru terbarukan yang dilakukan pemerintah, tentu harus disikapi dengan baik oleh generasi muda saat ini. Kemajuan teknologi dalam bidang kelistrikan harus mendorong para generasi muda untuk berfikir lebih kreatif dan inovatif. Dalam hal ini tentu saja peranan mahasiswa menjadi sangat penting. Misalnya saja ide kreatif dan inovatif terkait kendaraan bermotor berbasis energi listrik.

Mahasiswa Program studi Pendidikan Teknik Elektro Universitas PGRI Madiun, merupakan generasi muda yang diharapkan mampu mengambil peran dalam hal perkembangan teknologi energi baru terbarukan. Misalnya saja dalam hal perkembangan kendaraan bermotor yang berbasis kelistrikan. Tentu saja sebelum mencapai tahap yang lebih jauh, hal pertama yang perlu dikuasai mahasiswa adalah tentang konsep sistem kerja motor listrik.

Sebelumnya telah dilakukan penelitian terkait pemahaman konsep tentang motor induksi (Ihtiari \& Hendrik, 2019). Penelitian tersebut mengambil metode pembelajaran Problem Based Learning, dimana kemampuan mahasiswa dalam hal pemahaman konsep tentang motor induksi menunjukkan peningkatan dengan nilai rerata N-Gain medium. Selain itu penelitian tentang BLDC motor juga dilakukan terkait sistem pengaturan BLDC motor . Bagaimana sistem pengaturan kecepatan motor BLDC motor dibuat menggunakan sistem kontroler PID. Hal ini kedepannya dapat dimanfaatkan untuk kegiatan pembelajaran terkait sistem kontrol BLDC motor (Satiawan et all, 2014). Selanjutnya terkait BLDC motor motor juga pernah diteliti terkait pengembangan BLDC motor menggunakan mikrokontroler PIC. Dengan sistem ini memungkinkan peningkatan pada karakteristik keluaran motor BLDC motor (Salah et all, 2011). Selanjutnya penelitian terkait BLDC motor juga dilakukan oleh Mosavi dkk. Dimana Mosavi dkk merancang sistem kontrol BLDC motor yang hasilnya disimulasikan menggunakan MATTLAB (Mosavi, et all, 2012)

Berangkat dari kondisi energi di Indonesia serat didukung dengan banyaknya penelitian terkait BLDC motor dan pembelajaran mengenai motor listrik, maka kami mencoba melakukan penelitian terkait pemahaman konsep mengenai BLDC motor. Tujuan dari penelitian ini agar kedepannya pemahaman kosep mahasiswa terkait medan magnetik pada BLDC motor dapat diaplikasikan dalam prototype motor listrik, meski dalam tahap yang sederhana.

Penelitian pendahuluan telah dilakukan terkait bagaimana mahasiswa mampu memahami konsep menengai medan magnet pada motor induksi. Karena kedepan diharapkan mahasiswa mampu berinovasi terkait kendaraan motor listrik yang menggunakan BLDC motor.

Motor Brushless Direct Current (BLDC) adalah salah satunya jenis motor yang sangat cepat populer. Motor BLDC digunakan dalam industri seperti Peralatan, Otomotif, Dirgantara, Konsumen, Medis, Otomasi Industri (Yedamale, 2003). BLDC motor merupakan jenis motor yang memilik banyak keunggulan dibandingkan motor konvensional. Karena rotor terbuat dari magnet permanen, maka BLDC memiliki efisiensi yang lebih tinggi dan torsi awal yang tinggi. Metode pengendalian motor BLDC jauh lebih rumit untuk kecepatan dan torsi yang konstan, 
karena tidak adanya brush yang menunjang proses komutasi dan harga untuk motor BLDC jauh lebih mahal. Contoh perbandingan BLDC motor dan motor DC biasa misalnya pompa minyak pada mobil. Mobil yang menggunakan motor dc maksimal hanya bisa beroperasi 6.000 jam. Namun jika menggunakan BLDC motor, siklus operasinya bisa ditingkatkan hingga 15.000 jam atau hampir tiga kali lipat (Wahono dan Sutrisno, 2016). Sayangnya pengendalian variasi kecepatan motor BLDC mempunyai kompleksitas yang tinggi dan biayanya yang tinggi, karena pada umumnya menggunakan sensor posisi rotor dengan hall effect, resolver atau absolute sensor position

\section{METODE PENELITIAN}

Penelitian ini dilakukan di Program Studi Pendidikan Teknik Elektro, mengambil subyek penelitian mahasiswa sejumlah 12 orang. Mereka mengambil mata kuliah Workshop Pemanfaatan Energi Listrik. sebelumnya mereka telah menempuh mata kuliah Teori Medan dan Penggunaan dan Pengaturan Motor Listrik. Dari kedua mata kuliah sebelumnya, mereka sudah mendapatkan bekal terkait medan magnet pada motor listrik. Pada penelitian ini dikembangkan ke arah BLDC motor, yang dikemas dalam pembelajaran berbasis proyek. Di awal pembelajaran mahasiswa diberikan penjelasan terkait BLDC motor, yang dilanjutkan dengan proyek pembuatan prototype motor listrik berbasis BLDC. Teknik pengumpulan data dilakukan melalui penilaian kinerja yang meliputi kualitas produk yang dihasilkan, kedalaman pemahaman konten yang ditunjukkan, dan kontribusi yang diberikan pada proses realisasi proyek yang sedang berlangsung. Peningkatan pemahaman konsep mahasiswa mengenai BLDC motor, dilihat dari hasil akhir presentasi mengenai project yang dibuat. Dimana mahasiswa harus mampu menjelaskan sistem kerja BLDC motor mulai awal hingg sebuah prototype kendaraan motor listrik dapat bergerak.

\section{HASIL DAN PEMBAHASAN}

Hasil dari penelitian yang telah dilakukan, diperoleh hasil yang berkaitan dengan pemahaman konsep terkait BLDC motor. Diawali dengan study pendahuluan, dimana menggali seberapa jauh pemahaman mahasiswa tentang gaya magnet, dimana gaya magnet dirumuskan seperti persamaan 1 .

$$
F=B I L \sin \theta
$$

Kedua adalah konsep terkait kumparan dalam medan medan magnet. Seperti ditunjukkan gambar 1. Tampak dari gambar 1, koil memiliki konduktor efektif a-b dan c-d. Pada saat diberikan arus listrik, maka akan timbul gaya yang berlawanan arah (gambar 1b), dimana menyebabkan arus listrik menembus medan magnet. Dari peristiwa ini menibulkan adanya torka. Dimana nilai torka bergantung pula pada jumlah lilitan (N). Seperti ditunjukkan persamaan 2 .

$$
T_{D}=2 r F N=2 r B I L N=K_{\mathrm{T}} l
$$




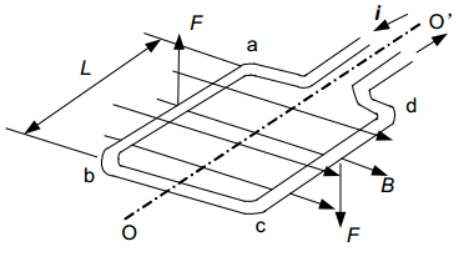

(a)

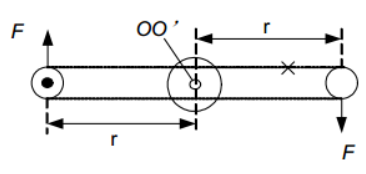

(b)

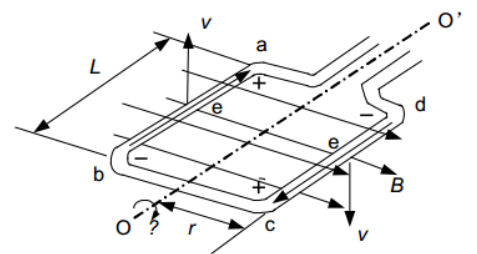

(c)

Gambar 1. Medan Manet

Pemahaman konsep selanjutnya terkait EMF atau electromotive force. Putaran koil pada medan magnet menimbulkan elektromotive force atau EMF. Besarnya EMF dapat dihitung dengan persamaan :

$$
E=B L v \sin \theta
$$

Dimana $\theta$ merupakan besar sudut antara B dan L. Semakin besar $\theta$ maka akan semakin besar pula induksi elektromagnetiknya.

Jika ketiga konsep tersebut telah dipahami dengan baik oleh mahasiswa, maka dilanjutkan dengan penjelasan mengenai konsep pada BLDC motor. Sebelumnya bisa dilihat dari gambar 2. Gambar 2 menunjukkan diagram BLDC sederhana satu fasa dan tiga fasa. Rotor mempunyai magnet permanen yang mengelilingi bagian stator.

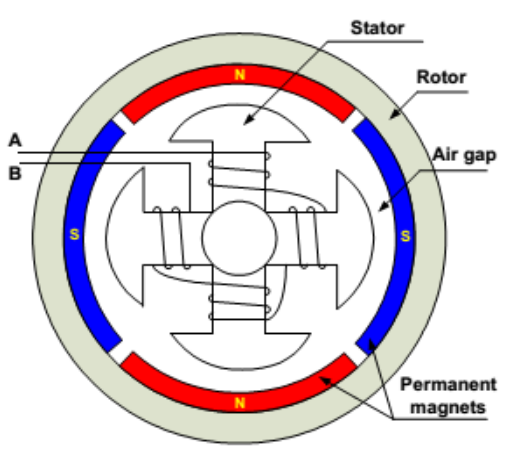

(a) Single-phase

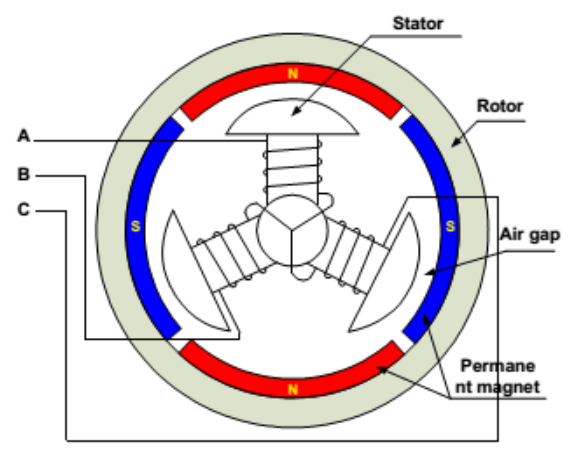

(b) Three-phase

Gambar 2. Diaram sederana BLDC motor satu dan tia fasa

Dari gambar 2, dapat diketahui perbedaan antara satu fasa dan tiga fasa. Motor satu fasa hanya memiliki satu lilitan stator dimana masing-masing lengan stator diputar searah atau berlawanan arah jarum jam untuk mengasilkan empat kutub seperti tampak pada gambar 2 . Sedangkan pada motor tiga fasa, terdapat tiga lilitan untuk stator. Dimana setiap fasa diaktifkan secara berurutan sehingga membuat rotor berputar.

Pengoperasian motor didasarkan pada gaya tarik atau tolak pada antar kutub manet (gambar 3). Dalam hal ini misalnya menggunakan motor tiga fasa. Ketika arus listrik mengalir pada lilitan kawat tembaga maka akan menghasilkan kutub magnet yang menarik magnet permanen terdekat yang berlawanan dari kutub yang dihasilkan. Jika arus menuju lilitan terdekatnya, maka rotor akan bergerak, demikian seterusnya sehingga motor bergerak sempurna. 

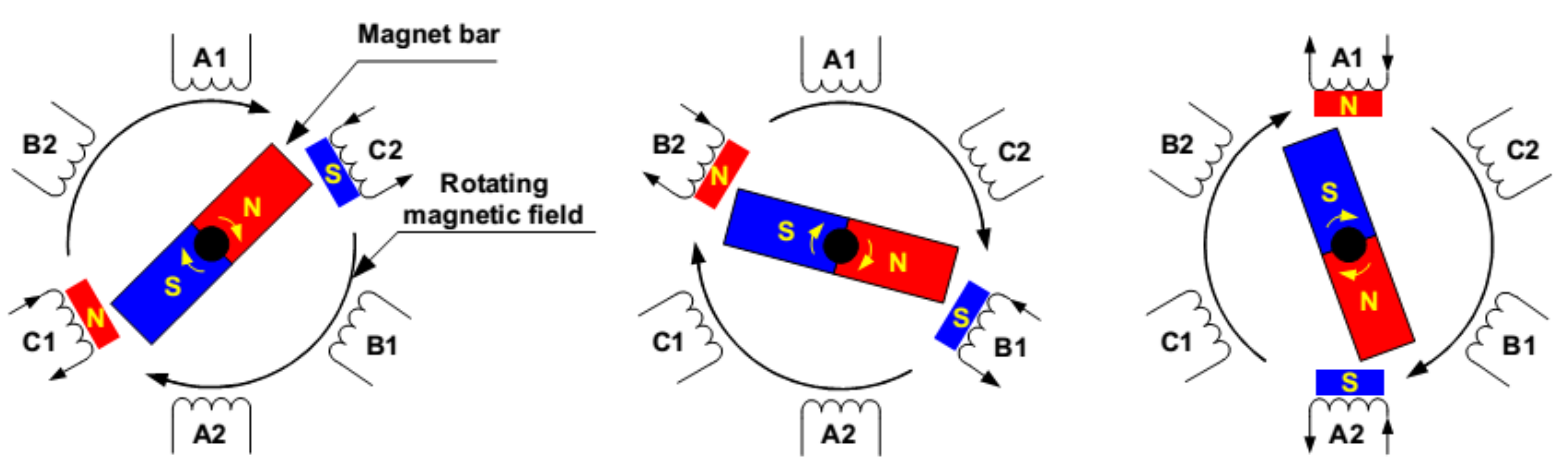

Gambar 3. Rotasi pada motor

Dari beberapa pemahaman tersebut, maka mahasiswa dibawa ke arah BLDC motor. Konsep BLDC pada dasarnya sama, pembedanya ada penambahan kontrol elektronik (gambar 4). Feedback pada BLDC menggunakan sensor yang disebut sensor hall. Disinilah perbedaan mendasar dari motor konvensional dan BLDC (Jian Zhao and Yangwei Yu, 2011).

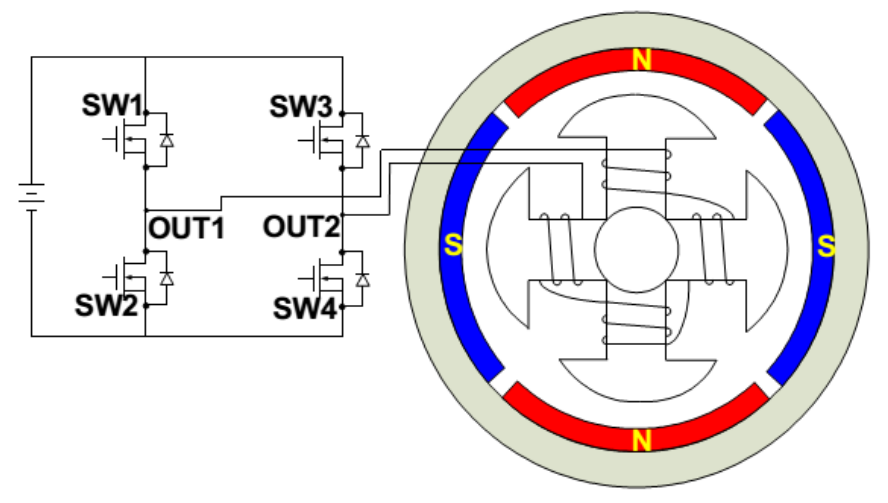

Gambar 4. Brusless DC motor

Dari keenam tahapan pemahaman konsep tersebut, mahasiswa diberikan proyek pembuatan prototype kendaraan motor listrik sederhana. Dimana dari proses pembelajaran yan telah dilakukan diperoleh hasil seperti pada tabel 1.

Tabel 1. Hasil proses pembelajaran

\begin{tabular}{|c|c|c|c|c|}
\hline \multirow{2}{*}{ No } & \multirow{2}{*}{ Aspect } & \multicolumn{3}{|c|}{ Result } \\
\hline & & Before & After & $N$-Gain \\
\hline 1. & Analisis besar gaya listrik $F=B I L \sin \theta$ & $83,3 \%$ & $91,6 \%$ & 0,43 \\
\hline 2. & $\begin{array}{l}\text { Konsep mengenai torka dengan persamaan } \\
\left(T_{D}=2 r F N=2 r B I L N=K_{\mathrm{T}} l\right) \text { dan mampu } \\
\text { menjelaskan terkait bagaimana kerja torka } \\
\text { pada BLDC motor }\end{array}$ & $41,6 \%$ & $83,3 \%$ & 0,56 \\
\hline 3. & $\begin{array}{l}\text { Pemahaman konsep terkait electromotive } \\
\text { force (EMF) dan menghubungkan persamaan } \\
E=B L v \sin \theta \text { dengan gambar }\end{array}$ & $66.7 \%$ & $91,6 \%$ & 0.49 \\
\hline
\end{tabular}




\begin{tabular}{llccc}
\hline \multirow{2}{*}{ No Aspect } & \multicolumn{3}{c}{ Result } \\
\cline { 2 - 4 } & Before & After & N-Gain \\
\hline
\end{tabular}

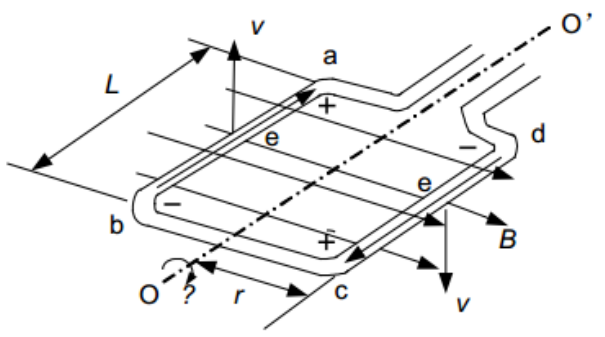

4. Menganalisis sistem gerak prototype motor $33.3 \%$ $66.7 \%$ 0,48 listrik berbasis BLDC. Dimana dilengkapi dengan penjabaran terkait bagaimana sebuah BLDC bekerja sehingga membuat prototype dapat berfungsi dengan baik.

Tabel 1 menunjukkan pemahaman konsep mahasiswa terkait sistem kerja sebuah BLDC motor, yang diawali dengan konsep awal tentang medan magnetik. Dimana prinsip BLDC motor diawali dangan pemahahaman tentang medan magnetik dan induksi elektromagnetik.

\section{KESIMPULAN}

Kesimpulan dari penelitian yang telah kami lakukan adalah konsep mengenai sistem kerja BLDC motor dapat dipahami dengan baik menggunakan model pembelajaran berbasis proyek. Proyek yang dihasilkan berupa prototype motor listrik yang sudah dapat digunakan dengan baik. Kemampuan mahasiswa terkait pemahaman konsep tentang medan magnet pada BLDC mengalami kanaikan dengan rata-rata nilai gain medium. Berdasarkan hasil penelitian tersebut, maka model pembelajaran project based learning sesuai jika diterapkan untuk pemahaman konsep medan magnetik.

\section{DAFTAR PUSTAKA}

Ihtiari \& Hendrik. (2019). Problem-Based Learning Model for Three-Phase Induction Motor. Jurnal Penelitian Fisika dan Aplikasinya (JPFA), Volume 09, Issue 01, June 2019.

Jian Zhao and Yangwei Yu. (2011). Brushless DC Motor Fundamentals Application Note. The Future of Analog IC Technologi (MPS).

Mosavi, et al (2012). Design of Efficient Adaptive Neuro-Fuzzy Controller Based on Supervisory Learning Capable for Speed and Torque Control of BLDC Motor. PRZEGLĄD ELEKTROTECHNICZNY (Electrical Review), ISSN 00332097, R. 88 NR 1a/2012.

Padmaraja Yedamale. (2003). Brushless DC (BLDC) Motor Fundamentals. Microchip Technology Inc.

Suharyati et al, (2019). Outlook Energi Indonesia. Sekretariat Jenderal Dewan Energi Nasional ISSN 25273000.

Salah et al. (2011). Development of a BLDC motor drive with improved output characteristics. PRZEGLACD ELEKTROTECHNICZNY (Electrical Review), ISSN 0033-2097, R. 87 NR 3/2011. 
Satiawan. 2014. Realisasi Sistem Pengaturan Kecepatan Motor BLDC Menggunakan DSP TI C2000 untuk Pengembangan Metode Belajar Mengajar Berbasis Aplikasi Praktis. Seminar Nasional Riset Inovatif II, Tahun 2014 issn : 2339-1553

Tri, W dan Tole, S. (2016) Skema Pengendali Motor BLDC Tanpa Sensor Posisi Rotor dengan Metode Deteksi Back EMF Berbasis Mikrokontroler Arduino. Jurnal Ilmu Teknik Elektro Komputer dan Informatika (JITEKI) Vol. 2, No. 2, Desember 2016 